\title{
Depolarizing GABA Acts on Intrinsically Bursting Pyramidal Neurons to Drive Giant Depolarizing Potentials in the Immature Hippocampus
}

\author{
Sampsa T. Sipilä, ${ }^{1}$ Kristiina Huttu, ${ }^{1}$ Ivan Soltesz,${ }^{3}$ Juha Voipio, ${ }^{1}$ and Kai Kaila ${ }^{1,2}$ \\ ${ }^{1}$ Department of Biological and Environmental Sciences and ${ }^{2}$ Neuroscience Center, University of Helsinki, FIN-00014 Helsinki, Finland, and ${ }^{3}$ Department of \\ Anatomy and Neurobiology, University of California, Irvine, California 92697-1280
}

\begin{abstract}
Spontaneous periodic network events are a characteristic feature of developing neuronal networks, and they are thought to play a crucial role in the maturation of neuronal circuits. In the immature hippocampus, these types of events are seen in intracellular recordings as giant depolarizing potentials (GDPs) during the stage of neuronal development when $\mathrm{GABA}_{\mathrm{A}}$-mediated transmission is depolarizing. However, the precise mechanism how GABAergic transmission promotes GDP occurrence is not known. Using whole-cell, cell-attached, perforated-patch, and field-potential recordings in hippocampal slices, we demonstrate here that CA3 pyramidal neurons in the newborn rat generate intrinsic bursts when depolarized. Furthermore, the characteristic rhythmicity of GDP generation is not based on a temporally patterned output of the GABAergic interneuronal network. However, GABAergic depolarization plays a key role in promoting voltage-dependent, intrinsic pyramidal bursting activity. The present data indicate that glutamatergic CA3 neurons have an instructive, pacemaker role in the generation of GDPs, whereas both synaptic and tonic depolarizing GABAergic mechanisms exert a temporally nonpatterned, facilitatory action in the generation of these network events.
\end{abstract}

Key words: GABAergic; network; hippocampus; development; pacemaker; glutamatergic neurons; activity

\section{Introduction}

Periodic spontaneous network events are generated by immature neuronal networks as shown in extensive studies on the hippocampus, cortex, retina, and spinal cord (Ben Ari et al., 1989; Garaschuk et al., 1998, 2000; Feller, 1999; O’Donovan, 1999; Ben Ari, 2001; Leinekugel et al., 2002). They are generally considered to be involved in the functional and structural development of neuronal circuits (Feller, 1999; Penn and Shatz, 1999; Katz and Crowley, 2002; Kandler, 2004; Kasyanov et al., 2004; Spitzer et al., 2004). Based on intracellular recordings in pyramidal neurons in vitro, the spontaneous events in the early postnatal rat hippocampus were originally termed giant depolarizing potentials (GDPs) (Ben Ari et al., 1989). These events are readily detected in extracellular field-potential (fp) recordings (Lamsa et al., 2000; Khazipov et al., 2004) and invade all hippocampal subfields, recruiting both GABAergic interneurons and glutamatergic principal neurons (Khazipov et al., 1997, 2001; Garaschuk et al., 1998; Hollrigel et al., 1998; Menendez de la Prida et al., 1998; Menendez de la Prida and Sanchez-Andres, 2000; Ben Ari, 2001). They have a duration of $0.5-2 \mathrm{~s}$ and a frequency of $0.1-0.3 \mathrm{~Hz}$ both in vitro

Received Jan. 27, 2005; revised March 24, 2005; accepted April 16, 2005

This work was supported by the Academy of Finland, the Sigrid Juselius Foundation (K.K., J.V.), and by National Institutes of Health Grant NS38580 (I.S.). We thank Dr. Richard Miles for helpful discussions and comments on a previous version of this manuscript.

Correspondence should be addressed to Kai Kaila, Department of Biological and Environmental Sciences, University of Helsinki, FIN-00014 Helsinki, Finland. E-mail: Kai.Kaila@Helsinki.Fi.

DOI:10.1523/JNEUROSCI.0378-05.2005

Copyright $\odot 2005$ Society for Neuroscience $\quad$ 0270-6474/05/255280-10\$15.00/0 and in vivo (Lamsa et al., 2000; Ben Ari, 2001; Leinekugel et al., 2002). Although $\mathrm{GABA}_{\mathrm{A}}$-mediated transmission promotes the occurrence of GDPs (Ben Ari et al., 1989; Garaschuk et al., 1998; Khalilov et al., 1999), it is notable that they are fully blocked by ionotropic glutamate antagonists (Ben Ari et al., 1989; Hollrigel et al., 1998; Bolea et al., 1999; Lamsa et al., 2000; Khazipov et al., 2001).

That GABAergic transmission is functionally excitatory in the neonate hippocampus has been demonstrated amply in previous work, showing that action-potential firing (Khalilov et al., 1999; Dzhala and Staley, 2003) as well as GDPs are inhibited by GABA $_{\mathrm{A}}$ antagonists (Ben Ari et al., 1989; Khalilov et al., 1999; Garaschuk et al., 1998) and that $\mathrm{GABA}_{\mathrm{A}}$ agonists increase GDP frequency (Khalilov et al., 1999; Lamsa et al., 2000). However, it is important to recognize that these findings do not explain how the excitatory GABAergic actions contribute to the rhythmic network activity characteristic of GDPs. In particular, rhythmic activity of the interneuronal network might drive GDPs, implying a "pacemaker" function for GABAergic activity. In contrast, GABAergic transmission might facilitate GDP occurrence by increasing the general level of network excitation. Finally, a mechanism that has to be addressed in the present context is the role of excitatory GABAergic transmission in synchronization of neuronal activity during GDPs.

The present experiments were performed in the CA3 area because this subfield has the highest propensity to produce GDPs (Ben Ari, 2001). Together, our data suggest that the depolarizing action of GABAergic transmission has a temporally nonpat- 
terned, facilitatory role in the generation of GDPs by promoting voltage-dependent bursting of immature CA3 pyramidal neurons. The CA3 pyramids with their characteristic bursting properties are responsible for shaping the temporal properties of GDP activity.

\section{Materials and Methods}

Wistar rat pups (postnatal days $0-6$, where day 0 refers to the day of birth) were decapitated, and the brains were dissected in cold $\left(0-4^{\circ} \mathrm{C}\right)$ oxygenated $\left(95 \% \mathrm{O}_{2} / 5 \% \mathrm{CO}_{2}\right)$ standard solution containing the following (in mM): $124 \mathrm{NaCl}, 3.0 \mathrm{KCl}, 2.0 \mathrm{CaCl}_{2}, 25 \mathrm{NaHCO}_{3}, 1.1 \mathrm{NaH}_{2} \mathrm{PO}_{4}$, $1.3 \mathrm{MgSO}_{4}$, and 10 D-glucose, $\mathrm{pH} 7.4$ at $32^{\circ} \mathrm{C}$. For electrophysiological recordings, coronal brain slices $(350-600 \mu \mathrm{m})$ were cut with a vibrating blade microtome (VT1000S; Leica, Nussloch, Germany) and allowed to recover at least for $1 \mathrm{~h}$ at $32^{\circ} \mathrm{C}$ before use.

Electrophysiological recordings. Individual slices were transferred into a submersion-type recording chamber perfused with standard solution $\left(32-33^{\circ} \mathrm{C}\right)$. Axopatch $200 \mathrm{~A}$ and $200 \mathrm{~B}$ amplifiers were used for whole-cell recordings. Patch pipettes had a resistance of 5-8 $\mathrm{M} \Omega$ when filled with the following (in $\mathrm{mM}$ ): $95 \mathrm{~K}$-gluconate, $40 \mathrm{KCl}, 5 \mathrm{NaCl}, 2 \mathrm{MgCl}_{2}$, and 10 HEPES, pH 7.2, with $\mathrm{KOH}$ or 140 Cs-methanesulfonate (CsMs), 2 $\mathrm{MgCl}_{2}$, and 10 HEPES, $\mathrm{pH} 7.2$, with $\mathrm{CsOH}$. The former intracellular solution was used for current-clamp recordings, and the latter intracellular solution was used for voltage-clamp recordings; the recorded voltage was corrected with a calculated -10 or $-13 \mathrm{mV}$ liquid junction potential, respectively (Barry, 1994). Measurement of cell input resistance was based on small hyperpolarizing deflections $(<10 \mathrm{mV})$ under voltage- and current-clamp conditions. All of the cells included in the analyses had a resting membrane potential or, when spontaneously active, a peak afterhyperpolarization (see Results) below $-55 \mathrm{mV}$. All of the intracellular recordings were from CA3 pyramidal neurons that were visually identified using infrared video microscopy (Stuart et al., 1993).

For perforated-patch recordings of membrane voltage (no current was injected), gramicidin D (Sigma, St. Louis, MO) was included in the $\mathrm{K}$-gluconate-based solution at a concentration of $50 \mu \mathrm{g} / \mathrm{ml}$ and applied to pipettes after prefilling of the tip with a gramicidin-free solution. In these recordings, the initial seal resistance was $>5 \mathrm{G} \Omega$, and series resistance at the beginning of the actual voltage recording was $<300 \mathrm{M} \Omega$.

Extracellular fp recordings were performed with conventional $\mathrm{NaCl}-$ filled (150 mm) glass capillary electrodes (tip diameter, 5-10 $\mu \mathrm{m}$ ) placed in the stratum pyramidale of area CA3.

Drugs. 2,3-Dioxo-6-nitro-1,2,3,4-tetrahydrobenzo[f] quinoxaline-7sulfonoamide (NBQX), D,L-AP-5, bicuculline methobromide, 6-imino3-(4-methoxyphenyl)-1(6H)-pyridazinebutanoic acid hydrobromide (SR 95531) (Gabazine), and isoguvacine hydrochloride were from Tocris Cookson (Bristol, UK), and picrotoxin was from Sigma. The concentration of NBQX and D,L-AP-5 was $10 \mu \mathrm{M}$ and $40 \mu \mathrm{M}$, respectively, unless stated otherwise. Picrotoxin was always applied at $100 \mu \mathrm{M}$; the concentrations used for the other drugs are given in Results.

Note on terminology. GDPs were observed originally in intracellular recordings, and it was already concluded at that time that they reflect network activity (Ben Ari et al., 1989). However, using the term GDP for both cellular and network events, which is often done in the literature, can be very confusing. During a network-level GDP, some pyramidal neurons in the immature hippocampus generate "large hyperpolarizing potentials" evoked by GABAergic transmission (Ben Ari et al., 1989). This most likely reflects the variation in the developmental stage (cf. Tyzio et al., 1999) and consequent variation in the level of KCC2 expression (Rivera et al., 1999; Khirug et al., 2005) among individual pyramidal neurons. In addition, bursts of action potentials riding on a slow depolarization, highly reminiscent of GDPs, are often seen in pyramidal neurons in the absence of a network event ("asynchronous" bursts) (see Fig. $2 A, D, E$ ). Therefore, we use the terms GDP and field GDP (fGDP) when referring to the network event recorded intracellularly and extracellularly (cf. Khazipov et al., 2004), respectively. fGDPs were identified on the basis of the characteristic slow, negative fp deflection (range: $20-100 \mu \mathrm{V}$, $0.5-2 \mathrm{~s}$; see the paired fp recording in Fig. $2 A$ for a synchronous event). In paired $\mathrm{fp}$ recordings, the electrode tips were placed $30-200 \mu \mathrm{m}$ apart.
Under these conditions, asynchronous spikes reflect unit activity (Draguhn et al., 1998).

Because GABAergic transmission is depolarizing in immature neurons (Ben Ari et al., 1989; Owens and Kriegstein, 2002; Yamada et al., 2004), the term sGABA-PSC was used for spontaneous GABAergic postsynaptic current instead of the conventional spontaneous IPSC.

Analysis. Data were low-pass filtered at $1.6 \mathrm{kHz}$ and digitized at $5 \mathrm{kHz}$ for analyses using the Clampfit (Molecular Devices, Foster City, CA) and Strathclyde Electrophysiology WinWCP and WinEDR (John Dempster, Glasgow, UK) programs and the software programmed under Labview (National Instruments, Austin, TX). The detection threshold for $\mathrm{fp}$ spikes was set at $>4$ SDs of baseline noise signal amplitude. Spontaneous network events (see Results) were detected with threshold set at halfmaximal amplitude. The amplitude of events used for quantification showed a variation of less than $\pm 15 \%$ under any given experimental condition. For cross-correlation histograms of spikes versus slow, negative fp shifts, a time window of $\pm 1 \mathrm{~s}$ from the network event onset was analyzed, and spikes occurring during this time window were excluded from analyses of asynchronous spikes (see Fig. $2 A, D, E, G$ ).

To measure the magnitude of the tonic $\mathrm{GABA}_{\mathrm{A}}$-mediated current, we first computed all-point histograms from primary data (Brickley et al., 1996). Then, the magnitude of the tonic current was estimated from peaks of fitted Gaussians obtained from these types of histograms. sGABA-PSCs are seen as an asymmetric "tail" on the positive side of the all-point histograms. Thus, when sGABA-PSCs were seen in primary recordings, bins with less than half of the maximal amplitude on the positive side were not used for the Gaussian fits (these bins are outlined by dots in Fig. $5 B$ ). Each all-point histogram included $20-40$ s of primary data.

sGABA-PSCs were detected using the Strathclyde Electrophysiology WinEDR program, and software programmed under Labview was used for computing autocorrelation histograms of sGABA-PSC intervals and their amplitude spectra. To analyze the rhythmicity of sGABA-PSCs, these autocorrelation histograms and their amplitude spectra were compared with the mean of 20 identical analyses on surrogate data that were obtained by randomly shuffling sGABA-PSC intervals.

Bandpass filtering was used to highlight unit or population events in the illustrations. Data are presented as mean \pm SEM.

\section{Results}

\section{Pacemaker properties of neonatal CA3 pyramids}

Under current clamp, in the presence of ionotropic glutamate and GABA antagonists (NBQX, AP-5, and picrotoxin), 44 of 65 neonatal CA3 pyramidal neurons showed spontaneous bursts of spikes, and 21 were silent at rest $(-70 \pm 1.2 \mathrm{mV})$. The input resistance of the cells was $1.2 \pm 0.1 \mathrm{G} \Omega$. In the spontaneously active cells, negative current injection led to silence, and in the silent neurons, positive current injection produced bursting activity. Bursts of spikes (Fig. $1 A$, inset) were preceded by a slow regenerative depolarization, which commenced at approximately $-60 \mathrm{mV}$, and followed by a slow afterhyperpolarization (sAHP) with a duration of $\sim 4 \mathrm{~s}$ when bursts occurred at a low frequency. The frequency of bursts was enhanced by an additional increase in the depolarizing current and was accompanied by a decrease in the amplitude and duration of the sAHP with little change in spike threshold (Fig. 1A).

Neurons showing a high amplitude of the slow membrane potential oscillation ( $>15 \mathrm{mV} ; 19$ of the 65 recorded cells), defined as the maximum difference between the spike threshold $(-50 \pm 0.7 \mathrm{mV} ; n=10)$ and peak of sAHP, were used for a more detailed characterization of the intrinsic bursting. In Figure $1 B$, the frequency of bursts is plotted as a function of peak sAHP, which shows that its lower limit is $\sim 0.2 \mathrm{~Hz}$ (data from 10 neurons recorded in the presence of NBQX, AP-5, and picrotoxin). An important finding with respect to the analysis of network behavior (see below) was that at frequencies below $\sim 0.2-0.3 \mathrm{~Hz}$, the 
coefficient of variation $(\mathrm{CV}$; an indicator of irregularity) of interburst intervals was high. With a very slight increase in frequency, there was an abrupt decrease of the $\mathrm{CV}$ to a stable level (Fig. 1C). A change in the frequency of bursts (range, $\sim 0.2-$ $1.4 \mathrm{~Hz}$ ) was not associated with a change in burst duration (190 $\pm 37 \mathrm{~ms}$ ), spike number per burst $(4.2 \pm 0.7)$, or intraburst spike frequency $(19 \pm 2.7 \mathrm{~Hz})$.

Voltage-dependent bursting in the whole-cell mode was observed also in the absence of the ionotropic synaptic antagonists (data not shown) (Menendez de la Prida and Sanchez-Andres, 2000). However, whole-cell recordings are complicated by intracellular dialysis with the pipette filling solution and by electrodeinduced shifts in resting membrane potential (Tyzio et al., 2003). To study the properties of intact neurons, we used the cell-attached recording configuration. In the absence of drugs, in nine neurons showing robust bursting of the kind illustrated in Figure $1 D$, the preferred frequency of bursts was seen as a peak at $\sim 0.3$ $\mathrm{Hz}$ as shown in the interspike interval (ISI) histogram in Figure $1 E$.

\section{Temporal relationships between unit bursts and fGDPs}

Previous results have shown that there is a stimulation intensity-dependent delay (up to $\sim 250 \mathrm{~ms}$ with low intensities) between an electric stimulus and the subsequent evoked GDP (Ben Ari et al., 1989). In addition, an increase in the frequency of depolarizing postsynaptic potentials (mostly GABAergic) to $\sim 15-20 \mathrm{~Hz}$ occurs in $\sim 15-50 \%$ of GDPs during their onset (Menendez de la Prida and SanchezAndres, 1999, 2000). These results support the view that synchronization is mediated via recurrent excitatory connections (Traub and Wong, 1982). Therefore, we asked whether fGDP onset is preceded by pyramidal bursting. We characterized the bursting activity of intact neurons in relation to fGDPs (see Materials and Methods for fGDP detection criteria) with paired fp recordings as well as simultaneous fp and cell-attached recordings. Unit bursts were frequently associated with fGDPs, whereas some of the bursts occurred independently, as asynchronous bursts (Fig. $2 A, D)$. A rapid increase in bursts of spikes was frequently seen just before fGDP onset, whereas in some recordings, nearly all spikes were confined to fGDPs (Fig. 2A, B, compare fp 1, fp 2). This was quantified with cumulative cross-correlation histograms that showed that the percentage of spikes preceding fGDPs varied from 2 to $72 \%$ between individual recordings (Fig. 2C). These data are consistent with the large variability among individual CA3 pyramidal neurons in their propensity to generate intrinsic bursts during fGDP initiation. In the overall data of eight $\mathrm{fp}$ and six cell-attached recordings, $31 \%$ of the unit spikes preceded fGDPs and $90 \%$ of the unit spikes occurred within a 420 ms period $(-135$ to $+285 \mathrm{~ms})$ from fGDP onset. The fGDP onset was defined as the time of half-maximal amplitude of the slow, negative fp deflection (see Materials and Methods). Together, these observations related to neuronal synchronization are strikingly similar to those made in studies on interictal-like bursts in the mature CA3 region, where pyramidal bursts increase network gain via recurrent excitatory connections (Traub and Wong, 1982). Notably, such a mechanism is consistent with the significant delays observed with stimulation-induced GDPs (see above).

Because whole-cell recordings are complicated by intracellular dialysis with the pipette filling solution and by electrodeinduced shifts in resting membrane potential, fp and cellattached recordings were used for the detailed analysis above. However, an example of an intrinsic burst preceding a GDP is illustrated in Figure 2D. Hyperpolarization of the membrane by negative current injection led to abolishment of asynchronous bursts in five of five experiments (data not shown).

In agreement with previous work (Ben Ari et al., 1989; Hollrigel et al., 1998; Bolea et al., 1999; Lamsa et al., 2000; Khazipov et al., 2001), bath application of NBQX and AP-5 invariably and completely blocked fGDPs $\left(n=12 ;\left[\mathrm{K}^{+}\right]_{\mathrm{o}}=3-5 \mathrm{mM}\right)$. However, in 8 of 12 recordings, unit bursting could still be seen with an average spike frequency of $0.6 \pm 0.2 \mathrm{~Hz}$ in the presence of the 
$\mathbf{A}$

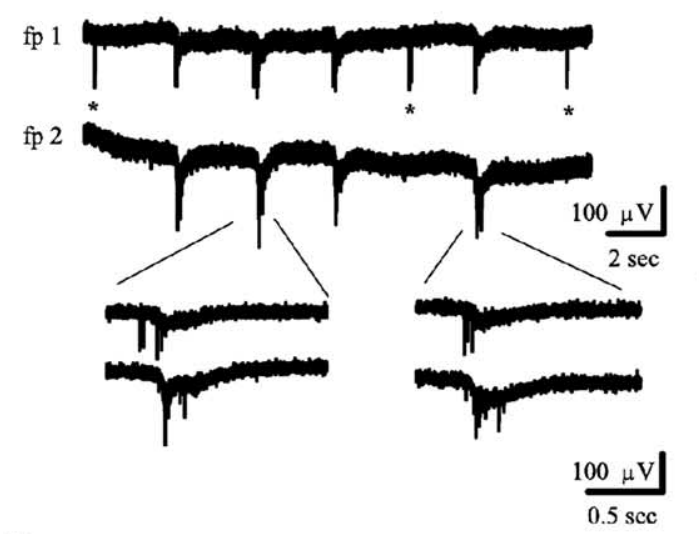

B

D

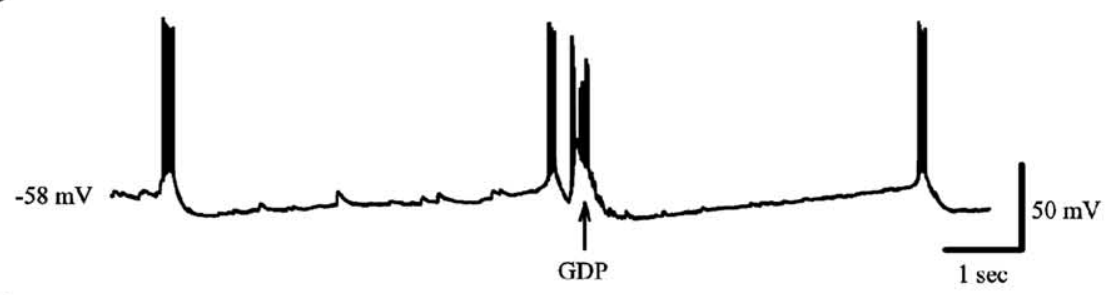

$\mathbf{E}$

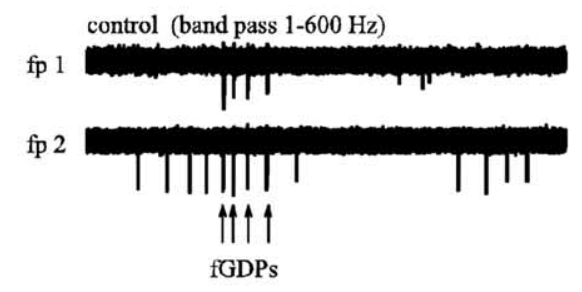

$\mathbf{F}$

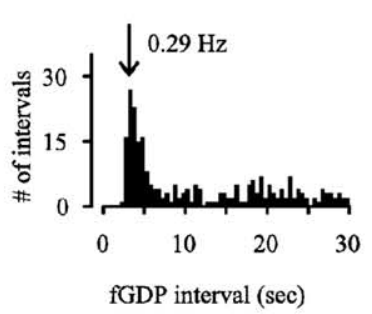

G

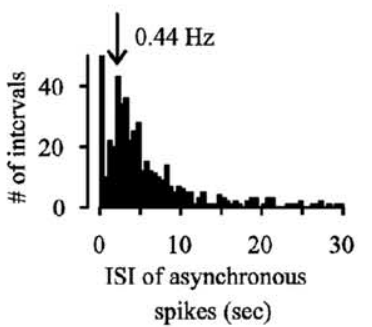

H

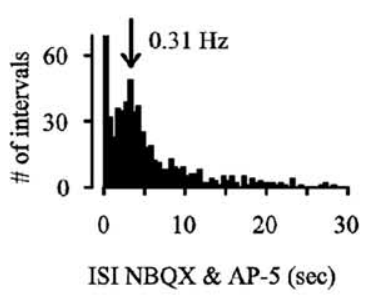

Figure 2. Temporal relationships between unit activity and GDPs. $\boldsymbol{A}$, Two simultaneous fp recordings (fp 1 and fp 2; $\sim 200 \mu \mathrm{m}$ apart) under control conditions show synchronous activity associated with slow, negative fp shifts (fGDPs) and unit asynchronous bursts (asterisk) (see Results). B, Cross-correlation histograms of slow, negative fp shifts and unit spikes (bin, $10 \mathrm{ms;} 56$ fGDPs) obtained from fp 1 and $\mathrm{fp} 2$ recordings of the experiment shown in A. C, Cumulative cross-correlation histograms of individual fp recordings $(n=8)$ and simultaneous fp and cell-attached $(n=6)$ recordings. $\boldsymbol{D}$, Intracellular recording showing intrinsic bursts and an intracellular GDP (arrow). Note that in the given recording, the intrinsic bursts and GDPs can be distinguished by eye, but this is not always the case. $\boldsymbol{E}$, Two simultaneous fp recordings (bandpass, 1-600 Hz) under control conditions show fGDPs (arrows), which are seen at both recording sites, and unit asynchronous bursts detected only at either site. A concentration of 10 $\mu \mathrm{M} \mathrm{NBQX}$ and $40 \mu \mathrm{M}$ D,L-AP-5 blocks fGDP, but unit bursting is still observed. $\boldsymbol{F}$, Histogram of fGDP intervals ( $n=14$ recordings; $n=668 \mathrm{fGDPs}$; bin, $0.5 \mathrm{~s}$ ). $\mathbf{G}$, ISI histogram of asynchronous spikes ( $n=696$ spikes from $5 \mathrm{fp}$ and 3 cell-attached recordings). $\boldsymbol{H}$, ISI histogram of unit activity in NBQX plus AP-5 $\left(\left[\mathrm{K}^{+}\right]_{0}=3-5 \mathrm{~mm}\right.$ ) obtained from four fp recordings ( $n=724$ spikes). The bin width is $0.5 \mathrm{~s}$, and the first bar related to intraburst spike intervals is truncated in the histograms in $\boldsymbol{G}$ and $\boldsymbol{H}$. Arrows in $\boldsymbol{F}$ - $\boldsymbol{H}$ indicate preferred frequency.

drugs (vs $1.0 \pm 0.3 \mathrm{~Hz}$ in control; $p=0.023$ ) (Fig. $2 E$ ). These results are consistent with the view that recurrent glutamatergic connections between bursting CA3 pyramids are required for synchronization during fGDPs.

The mean frequency of fGDPs was $0.02 \pm 0.005 \mathrm{~Hz}$ in the presence of $3 \mathrm{~mm}\left[\mathrm{~K}^{+}\right]_{\mathrm{o}}$. However, the distribution of fGDP intervals was not symmetrical and in the overall data had a pronounced peak at $\sim 3.5 \mathrm{~s}$, which indicates a preferred frequency of $\sim 0.3 \mathrm{~Hz}$ (Fig. $2 \mathrm{~F}$ ). Notably, the interval distribution of asynchronous unit burst activity observed during inter-fGDP intervals in the absence of drugs had a peak at a similar value, at $2.5 \mathrm{~s}(\sim 0.4 \mathrm{~Hz})$ (Fig. $2 G$ ). Furthermore, the interval distribution of the unit burst activity observed in the presence of glutamate antagonists peaked at $3.5 \mathrm{~s}(\sim 0.3 \mathrm{~Hz})$ (Fig. $2 \mathrm{H})$. This novel finding shows that the preferred frequency of unit bursting in the presence and absence of glutamate blockers is similar to the preferred frequency of fGDPs, which provides additional support for the key role of intrinsic bursting properties of CA3 pyramids in shaping the network events.

\section{Effect of tonic depolarization on fGDP rhythmicity}

The data obtained so far show that some of the CA3 pyramidal cells are occasionally bursting in their oscillatory voltage window, whereas others are activated only during fGDPs. The hypothesis that fGDPs are paced by pyramidal bursting leads to an additional prediction: a tonic depolarization driving most CA3 pyramids into their oscillatory voltage window should result in a stable fGDP rhythmicity at a frequency band identical to that of the stable bursting of pyramidal neurons (greater than $\sim 0.2-0.3 \mathrm{~Hz}$ ) (Fig. 1C). This prediction was tested using elevated $\left[\mathrm{K}^{+}\right]_{\mathrm{o}}$ as well as isoguvacine, a specific $\mathrm{GABA}_{\mathrm{A}}$ agonist that has been shown to depolarize neonatal CA3 neurons (Ben Ari et al., 1989). Isoguvacine $(0.25-1.5 \mu \mathrm{M})$ increased fGDP frequency (Fig. $3 A_{1}, C$ ) and stabilized it at $\sim 0.2-0.4 \mathrm{~Hz}$. In four of four experiments, this was seen as a narrow, Gaussian-like fGDP interval distribution (Fig. $3 \mathrm{~A}_{2}$ ) with a decrease in the $\mathrm{CV}$ of fGDP intervals. Similarly, elevation of $\left[\mathrm{K}^{+}\right]_{\mathrm{o}}$ resulted not only in an increase in fGDP frequency (Fig. $3 B_{1}, C$ ), but, notably, the fGDP interval distribution became narrower with a Gaussian-like shape when the average fGDP frequency reached a value of $\sim 0.2 \mathrm{~Hz}$ (Fig. $3 B_{2}$ ). A scatter plot showing the $\mathrm{CV}$ of fGDP intervals versus their mean frequency is illustrated in Figure $3 D$ and was strikingly similar to the corresponding plot related to intrinsic bursts of immature CA3 pyramidal neurons (Fig. 1C). Although the fGDP interval distribution shows a pronounced peak at $\sim 3.5$ $s$ in the overall data (Fig. $2 F$ ), this was not seen in those individual recordings in which the mean fGDP frequency under standard conditions was very low (Fig. $3 B_{2}$ ). However, also in these experiments, tonic depolarization resulted in a peak in the fGDP inter- 
val distribution at greater than $\sim 0.2 \mathrm{~Hz}$. As could be expected, a decrease in $\left[\mathrm{K}^{+}\right]_{\mathrm{o}}$ from its control level $3 \mathrm{~mm}$ to $1-2 \mathrm{~mm}$ resulted in a near-complete abolishment of fGDPs $(n=4)$ (Fig. $3 C)$. The novelty of these findings is that the dependency of fGDP rhythmicity on depolarization can be accurately predicted from the voltage-dependent bursting behavior of the CA3 pyramids.

Consistent with previous findings under control conditions (Ben Ari, 2001; Leinekugel et al., 2002), simultaneous voltage-clamp and $\mathrm{fp}$ recordings showed that rhythmic bursts of sGABA-PSCs occurred synchronously with fGDPs in elevated $\left[\mathrm{K}^{+}\right]_{\mathrm{o}}(7 \mathrm{~mm} ; n=6)$ (Fig. $4 A$ ). In Figure $4 B$, superimposed crosscorrelation histograms of sGABA-PSCs versus fGDPs and unit spikes versus fGDPs show that interneuronal activity increases in parallel with the activity of pyramidal neurons during fGDP generation. However, unit pyramidal spikes are concentrated to the beginning of fGDPs, whereas the sGABA-PSCs are more evenly distributed and occur within a longer time window. The autocorrelation histograms of sGABA-PSCs had side peaks at intervals of $3.8 \pm 0.2 \mathrm{~s}$, whereas clear peaks were absent in autocorrelation histograms based on surrogate data (Fig. $4 C_{1}$ ) (see Materials and Methods). Correspondingly, the amplitude spectra of the autocorrelation histograms showed a robust periodicity with a peak at $\sim 0.2-0.3 \mathrm{~Hz}$, which was not seen in spectra based on surrogate data $(n=6)$ (Fig. $\left.4 C_{2}\right)$. This indicates that the interneuronal network is undergoing robust network oscillations with a periodicity similar to that of fGDPs. However, an important observation was that application of NBQX $(10-40 \mu \mathrm{M})$ and AP-5 $(40-120 \mu \mathrm{M})$ abolished the sGABA-PSC rhythmicity as well as fGDPs but not unit bursting seen in the extracellular recordings $(n=6)$ (Fig. $4 A, D)$. This indicates that the rhythmic activity of interneurons is not an intrinsic property of the interneuronal network but is paced by glutamatergic neurons.

\section{Immature CA3 pyramidal neurons receive a strong tonic GABAergic input}

In voltage-clamp recordings with the CsMs-based pipette filling solution (see Materials and Methods) and a holding potential of 0 $\mathrm{mV}$, bath application of the $\mathrm{GABA}_{\mathrm{A}}$ antagonist bicuculline (10 $\mu \mathrm{M}$ ) blocked sGABA-PSCs and reduced the holding current by $6.7 \pm 0.84 \mathrm{pA}(n=10)($ Fig. $5 A, B)$. Consistent with a reduction in current noise by bicuculline, the SD of the Gaussian fit was reduced by $35 \pm 0.049 \%(n=10 ; p=0.0006)$. Cell input resistance was increased by $43 \pm 10 \%(n=4 ; p=0.046)$. Picrotoxin $(100 \mu \mathrm{M})$ also blocked sGABA-PSCs and reduced the holding current by $8.6 \pm 0.9 \mathrm{pA}(n=13)$ (Fig. $5 E)$. These data show that immature CA3 pyramidal neurons receive a pronounced tonic
$\mathbf{A}_{2}$

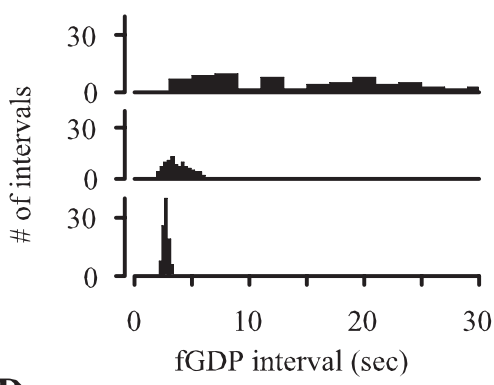

D

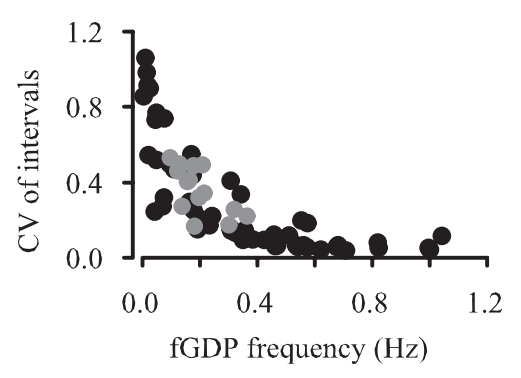

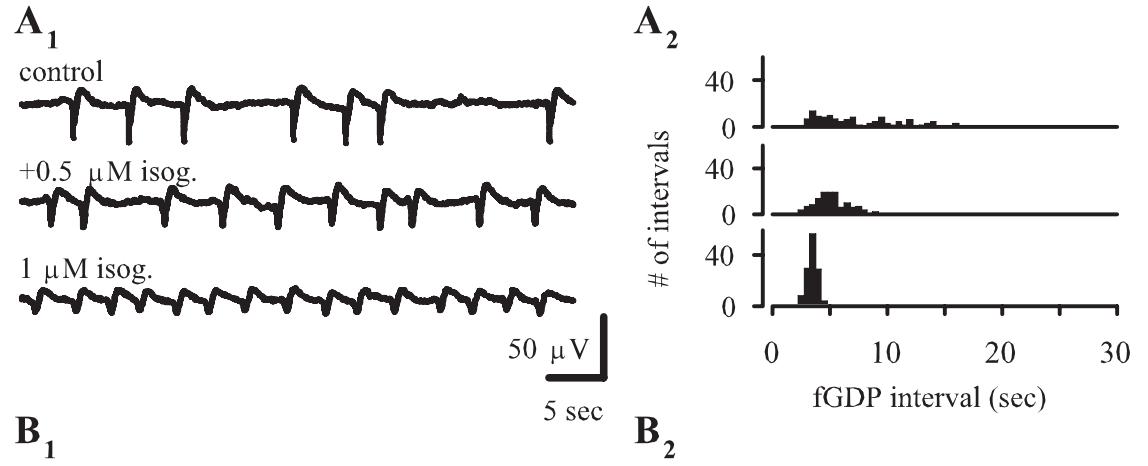

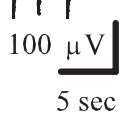

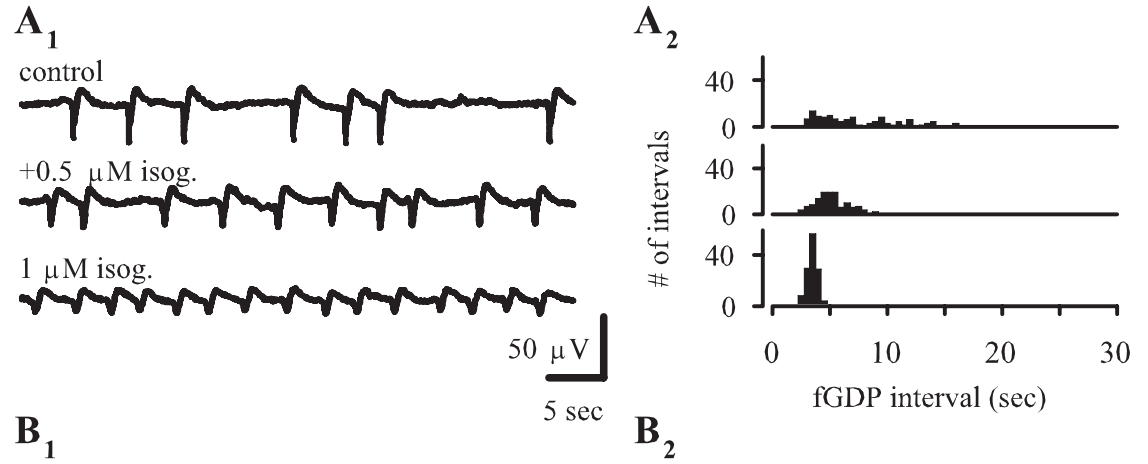

Figure 3. Influence of enhanced tonic excitation on network rhythmicity. $A_{1}$, fp recording showing an increase in fGDP frequency induced by isoguvacine (isog.; $0.5-1 \mu \mathrm{m} ;\left[\mathrm{K}^{+}\right]_{0}$ constant at $5 \mathrm{~mm}$; bandpass, $0.1-5 \mathrm{~Hz}$ ). $A_{2}, \mathrm{fGDP}$ interval histograms from in shown in $\boldsymbol{A}_{1} . \boldsymbol{B}_{1}$, fp recording with fGDPs at varying levels of $\left[\mathrm{K}^{+}\right]_{0}$ (bandpass, $0.1-40 \mathrm{~Hz}$ ). $\boldsymbol{B}_{2}$, Corresponding

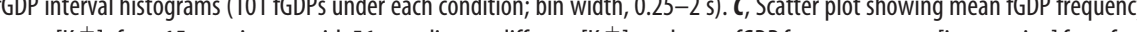
㢦 ${ }_{0}^{+}$from 15 experiments with 56 recordings at different $\left[\mathrm{K}^{+}\right]_{0}$ and mean $\mathrm{fGDP}$ frequency versus [isoguvacine] from fou experiments with 14 recordings at different isoguvacine concentrations. $\boldsymbol{D}$, Scatter plot of the CV of fGDP intervals versus mean frequency from the same experiments as in $\boldsymbol{C}$.

(most likely extrasynaptic) $\mathrm{GABA}_{\mathrm{A}}$-mediated input (Brickley et al., 1996; Farrant and Nusser, 2005).

The mean total charge transfer mediated by $\mathrm{GABA}_{\mathrm{A}}$ receptors was calculated as the time integral of the difference between the current in control solution and in the presence of bicuculline (Fig. $5 C$, shaded area). The mean total charge transfer conveyed by the tonic current was estimated by multiplying the value of the tonic current obtained from the all-point histograms (Fig. 5B) by time (Fig. $5 C$, area between the dotted lines). The contribution of the tonic current to the total $\mathrm{GABA}_{\mathrm{A}}$-mediated charge transfer was $87 \pm 3 \%(n=10)$ during the inter-GDP intervals (i.e., periods when asynchronous unit bursts are seen).

Another $\mathrm{GABA}_{\mathrm{A}}$ antagonist, SR 95531, has been shown to have a stronger inhibitory effect on phasic than on tonic (extrasynaptic) GABA action (Bai et al., 2001; Stell and Mody, 2002). With concentrations of $0.2,0.4,3$, and $10 \mu \mathrm{M}$, we observed a dose-dependent reduction in the baseline current (Fig. $5 D, E$ ). SR $95531(3-10 \mu \mathrm{M})$ completely blocked sGABA-PSCs, and its effect on the tonic component was significantly lower at $10 \mu \mathrm{M}$ than that of $10 \mu \mathrm{M}$ bicuculline (Fig. $5 E$ ). The fact that a significant 
$\mathbf{A}$

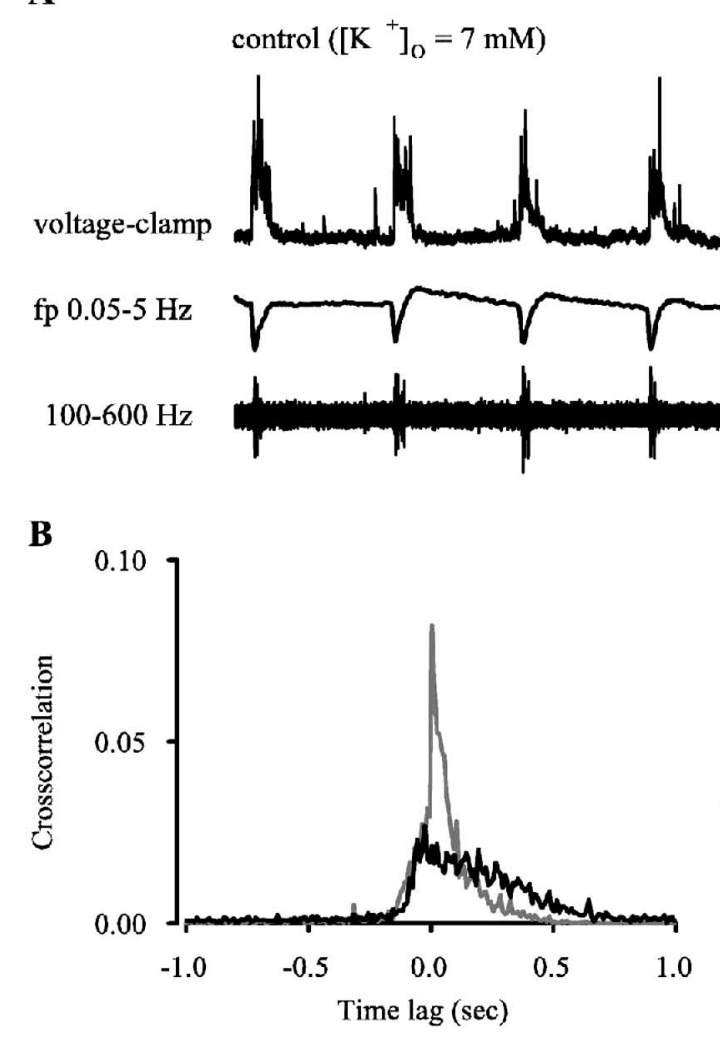

+ NBQX, AP-5
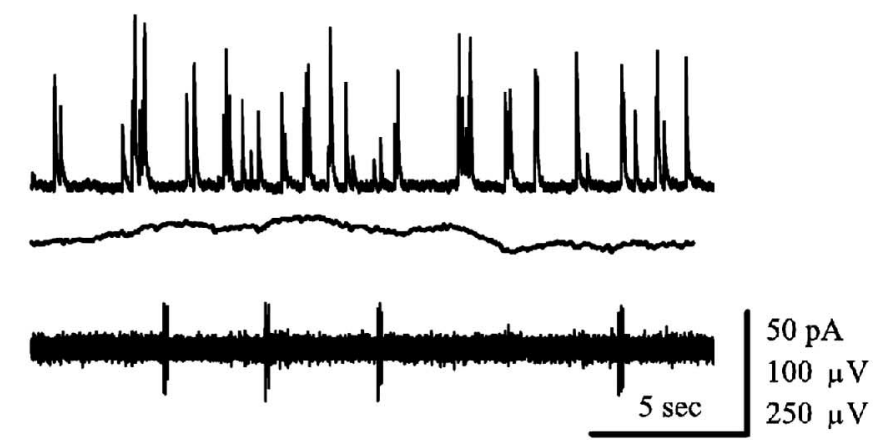

$\mathrm{C}_{1}$

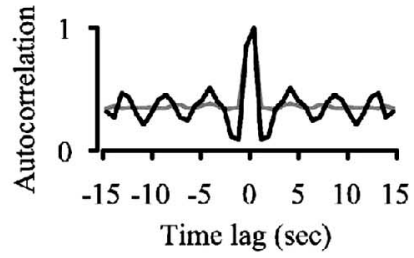

$\mathrm{C}_{2}$

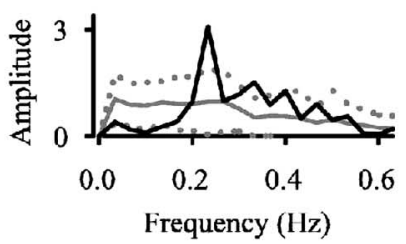

D 1

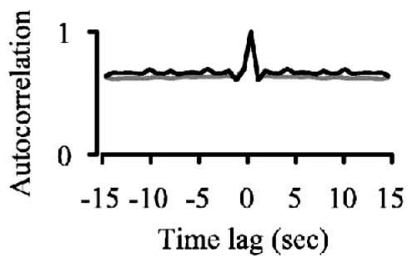

$\mathbf{D}_{2}$

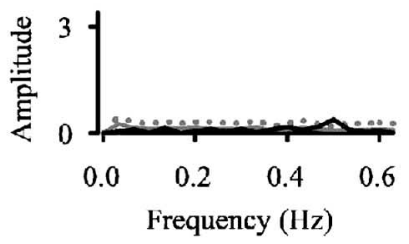

Figure 4. Rhythmic activity of interneurons at the preferred fGDP frequency is entrained by glutamatergic neurons. $A$, Simultaneous voltage-clamp recordings ( $0 \mathrm{mV}$; low-chloride filling solution) and fp recordings in $7 \mathrm{~mm}\left[\mathrm{~K}^{+}\right]_{0}$ show bursts of $\mathrm{SGABA}$-PSCs associated with fGDPs and the effect of NBQX and AP-5. The same fp recording is shown at two different bandwidths to illustrate the slow, negative fp shifts (fGDPs) and the associated fp spikes. Note the presence of unit fp bursts and the absence of fGDPs in the presence of the drugs. $B$, Cross-correlation histograms of $s G A B A-P S C s$ versus fGDPs (black line) obtained from seven voltage-clamp recordings and unit spikes versus fGDPs (gray line) based on data from eight fp and six cell-attached recordings. Zero time of $x$-axis is set at half-maximum of fGDP (see Materials and Methods). $\boldsymbol{C}_{\boldsymbol{D}} \boldsymbol{D}$, Autocorrelation histograms of SGABA-PSC intervals and their power spectra (black line) in the absence $\left(\boldsymbol{C}_{1}, \boldsymbol{C}_{2}\right)$ and presence $\left(\boldsymbol{D}_{1}, \boldsymbol{D}_{2}\right)$ of the blockers. The gray lines indicate the surrogate mean $(\boldsymbol{C}, \boldsymbol{D})$, and the dotted gray lines indicate $\pm 2 \operatorname{SDs}\left(\boldsymbol{C}_{2}, \mathbf{D}_{2}\right)$.

portion of the tonic $\mathrm{GABA}_{\mathrm{A}}$ current was not inhibited with $3 \mu \mathrm{M}$ SR 95531, whereas a complete block of sGABA-PSCs was seen, was made use of in additional experiments on the role of GABAergic actions on fGDP generation (Fig. 8A,B) (see below).

\section{GABAergic facilitation of unit activity}

In the presence of AP-5 and NBQX, further addition of the $\mathrm{GABA}_{\mathrm{A}}$ antagonists (picrotoxin or bicuculline) blocked the unit activity that was identified in paired fp recordings (Fig. 6A). Notably, when $\left[\mathrm{K}^{+}\right]_{\mathrm{o}}$ was thereafter elevated in steps of $1 \mathrm{~mm}$, unitbursting activity recovered (Fig. $6 A$ ) with a threshold at $5-8 \mathrm{~mm}$ $\left[\mathrm{K}^{+}\right]_{\mathrm{o}}$, and the ISI distribution peaked again at $5 \mathrm{~s}(\sim 0.2 \mathrm{~Hz})$ (Fig. $6 B$ ). Unit bursting could be induced by $\left[\mathrm{K}^{+}\right]_{\mathrm{o}}$ elevation in the presence of synaptic blockers also in recordings in which asynchronous activity was not detected under control conditions, demonstrating that bursting can be induced in silent CA3 neurons by tonic depolarization.

The actions of endogenous GABA on the neonatal pyramidal neurons were also studied with gramicidin-perforated patching (Kyrozis and Reichling, 1995). In five of five experiments, spontaneous activity was blocked by bath application of $10 \mu \mathrm{M}$ bicuculline with a concomitant hyperpolarization (Fig. 6C) of the membrane by $2-10 \mathrm{mV}$, in which larger hyperpolarizations were seen in cells with a more positive value of the resting membrane potential in control (range, -55 to $-68 \mathrm{mV}$ ).
Facilitation of rhythmic network activity by endogenous GABA

In agreement with previous observations (Ben Ari et al., 1989; Garaschuk et al., 1998; Khalilov et al., 1999), $10 \mu \mathrm{M}$ bicuculline completely blocked fGDPs seen in field recordings in seven of nine experiments (Fig. 7A), and in the remaining two experiments, there was a marked fall in frequency. In experiments in which application of bicuculline fully blocked fGDPs, elevation of $\left[\mathrm{K}^{+}\right]_{\mathrm{o}}$ always induced a recovery of population activity [termed non-GABA events (NGEs)] that was, in many respects, similar to fGDPs seen under control conditions (Fig. 7A-D).

During NGEs, $90 \%$ of the spikes were confined to a $390 \mathrm{~ms}$ period, $-155 \mathrm{~ms}$ to $+235 \mathrm{~ms}$, from the half-maximum of the slow, negative fp shift (Fig. $7 B$ ). This indicates that unit burst durations as well as their temporal relationship to the network activity are similar for both NGEs and fGDPs. Furthermore, the NGE frequency showed a dependence on extracellular potassium with, notably, a clear shift toward higher $\left[\mathrm{K}^{+}\right]_{\mathrm{o}}$ levels compared with fGDPs under control conditions (Fig. 7C). The requirement of a higher $\left[\mathrm{K}^{+}\right]_{\mathrm{o}}$ for a given increase in NGE versus fGDP frequency is in good agreement with our general idea of a temporally nonpatterned depolarizing role for GABA in fGDP generation. Finally, the CV versus the mean NGE frequency plot showed a similar abrupt decrease at $\sim 0.2-0.3 \mathrm{~Hz}$ as the fGDPs (Fig. $7 D$ ). This suggests that variations in the intervals of both NGEs and fGDPs are shaped by the interburst intervals of CA3 pyramidal 
neurons during imposed depolarizations with variable magnitudes (see above) (Fig. $1 C)$.

Tonic GABA action in the absence of interneuronal input enhances fGDPs

Next we examined whether the tonic GABA action can promote rhythmic population activity. The endogenous tonic $\mathrm{GABA}_{\mathrm{A}}$ conductance cannot be selectively blocked with any available antagonist (Fig. 5) (Brickley et al., 1996; Bai et al., 2001; Demarque et al., 2002; Stell and Mody, 2002; Semyanov et al., 2003; Farrant and Nusser, 2005). Therefore, we first applied SR 95531 at a concentration of $3 \mu \mathrm{M}$ in voltage-clamp experiments to block phasic GABA actions (i.e., sGABA-PSCs) (Fig. $8 A$ ). Thereafter, $4-32 \mu \mathrm{M}$ isoguvacine was applied to selectively enhance the tonic GABA current. The application of $10 \mu \mathrm{M}$ isoguvacine increased the baseline current $(17.7 \pm 3.0 \mathrm{pA} ; n=4 ; p=0.01)$ without evoking sGABA-PSCs, and this increase was blocked by picrotoxin (Fig. $8 \mathrm{~A}$ ). In $\mathrm{fp}$ recordings, SR $95531(3-10 \mu \mathrm{M})$ did not abolish fGDPs in seven of seven experiments (Fig. $8 B$ ). However, it led to a marked decrease in fGDP frequency to $11.3 \pm 3.7 \%$ (range, $1.5-32 \%$ ) from control. The smaller inhibitory effect of SR 95531 versus bicuculline on fGDP frequency is most likely explained by the remaining tonic GABA current (Fig. 5E). Notably, in six of six experiments, isoguvacine $(4-32 \mu \mathrm{M})$ increased the frequency of fGDPs in a dose-dependent manner by a factor of 4-20 from the level observed in the presence of $3 \mu \mathrm{M}$ SR 95531 (Fig. $8 B$ ). This result supports the conclusion that a temporally patterned output for the interneuronal network is not required for the promotion of fGDPs by depolarizing GABAergic transmission.

\section{Discussion}

Although the synaptic basis of fGDP generation has gained a lot of attention, pointing to a functionally excitatory role of $\mathrm{GABA}_{\mathrm{A}}$ receptor-mediated actions (see Introduction), there is surprisingly little information available on the mechanisms that govern this type of network rhythmicity in the immature hippocampus. Several lines of evidence obtained presently lead to the conclusion that the key action of GABA is to depolarize the CA3 pyramidal neurons to their burstgenerating voltage window. This intrinsic bursting of the CA3 pyramids is in turn responsible for the preferred fGDP frequency of $\sim 0.3 \mathrm{~Hz}$ seen in vitro. Notably, a peak at this frequency is also seen in recordings of spontaneous network activity in the immature hippocampus in vivo (Leinekugel et al., 2002).

A key role for intrinsic firing properties in the generation and Bicuculline; SR, SR 95331.

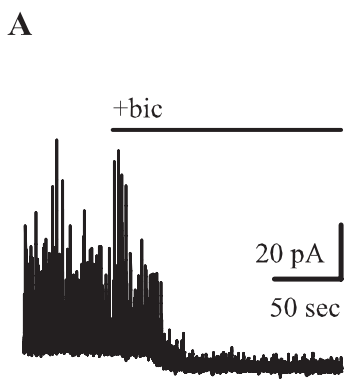

B

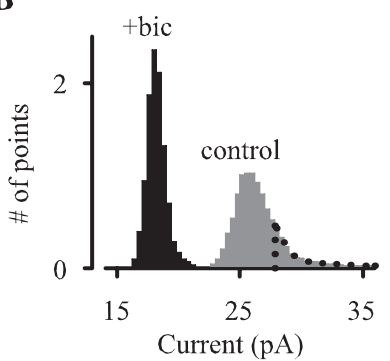

C

D

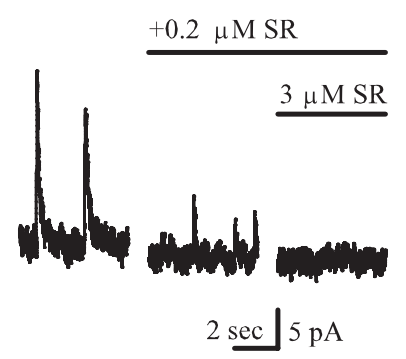

$\mathbf{E}$

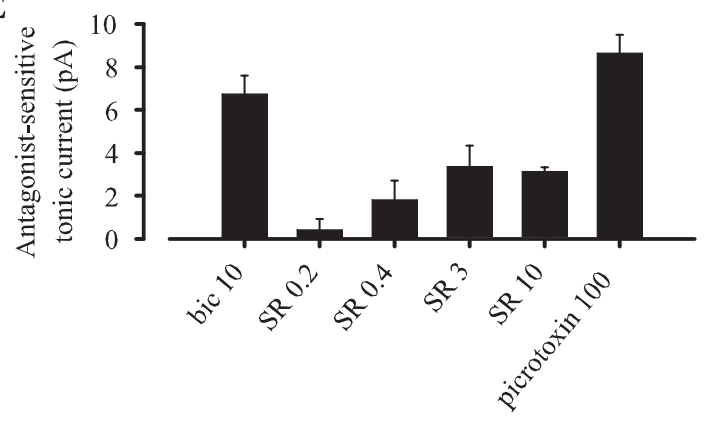

Figure 5. Tonic and phasic GABA actions on immature CA3 pyramidal neurons. A, Voltage-clamp recording ( $0 \mathrm{mV}$; low-chloride filling solution) showing a bicuculline-sensitive $(10 \mu \mathrm{m})$ tonic current (low-pass, $100 \mathrm{~Hz})$. B A All-point histogram computed from the recording in $\boldsymbol{A}$. The bins encircled with the dotted line were not used for Gaussian fits to reduce the influence of SGABA-PSCs on the estimate of the tonic current (see Materials and Methods). C, Superimposed specimen traces in control and with bicuculline. The dotted lines indicate the level of mean tonic current obtained from all-point histograms of the kind shown in $\boldsymbol{B}$. The area between the dotted lines represents charge transfer conveyed by the tonic current component, whereas the shaded area reflects the total bicuculline-sensitive charge transfer. $\boldsymbol{D}$, Voltage-clamp recording under control conditions and in the presence of SR 95331. E, Bar graphs showing the inhibition of tonic current by different concentrations (micromolar) of $\mathrm{GABA}_{\mathrm{A}}$ antagonists. bic,

$\mathbf{A}$

in NBQX, AP-5

(band pass $1-600 \mathrm{~Hz}$ )

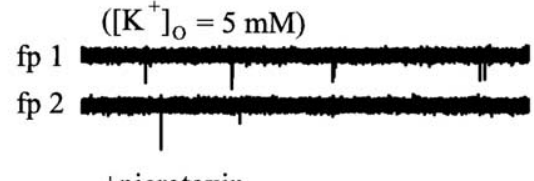

+ picrotoxin

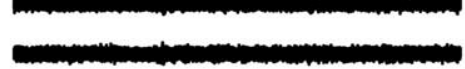

$\rightarrow\left[\mathrm{K}^{+}\right]_{\mathrm{O}}=8 \mathrm{mM}$

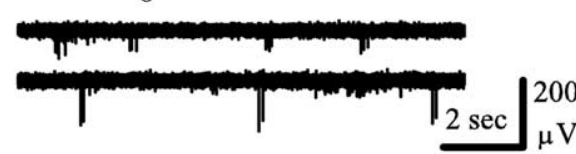

Figure 6. Endogenous GABA facilitates unit-bursting activity. $A$, Simultaneous fp recordings ( $f p$ 1 and $f p 2$; bandpass, 1-600 $\mathrm{Hz}$ ) in the presence of AP- 5 and NBQX showing units bursts that are blocked by picrotoxin. Thereafter, bursts were re-induced by elevating $\left[\mathrm{K}^{+}\right]_{0}$ in $1 \mathrm{~mm}$ steps to $8 \mathrm{~mm}$ to reach the threshold for spike activity in the presence of the blockers. $\boldsymbol{B}$, ISI histogram obtained at a minimum level of elevated $\left[\mathrm{K}^{+}\right]_{0}$ that induced unit bursting (preferred frequency, $0.21 \mathrm{~Hz}$ ) in the presence ionotropic glutamatergic and GABAergic antagonists (pooled data from $5 \mathrm{fp}$ recordings; $n=503$ spikes). C, Gramicidin perforatedpatch recording under control conditions and with the addition of $10 \mu \mathrm{m}$ bicuculline. Spikes are truncated.

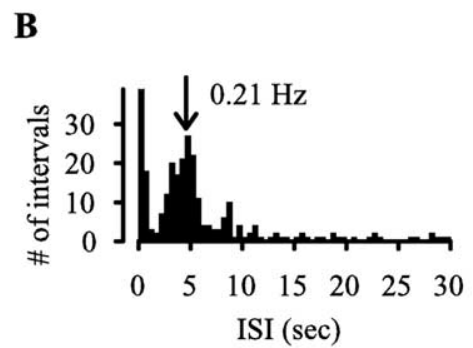

C

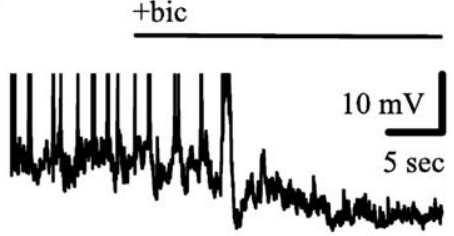

patterning of network oscillations has been amply demonstrated in various neuronal structures including the thalamus, neocortex, cerebellum, brain stem, spinal cord, and mature hippocampus (Llinas, 1988; Smith et al., 1991; Steriade et al., 1993; Hutcheon and Yarom, 2000; Marder and Bucher, 2001). We show here that voltage-dependent intermittent bursting is an intrinsic property of immature CA3 pyramidal neurons that is seen in the 
$\mathbf{A}$
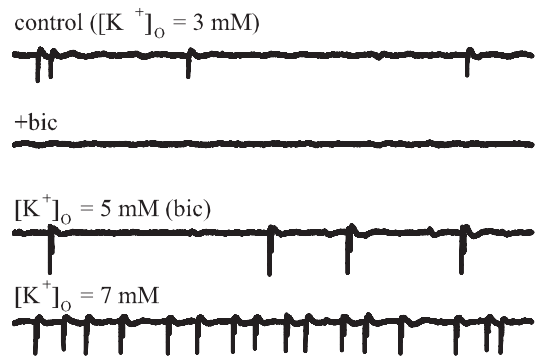

C
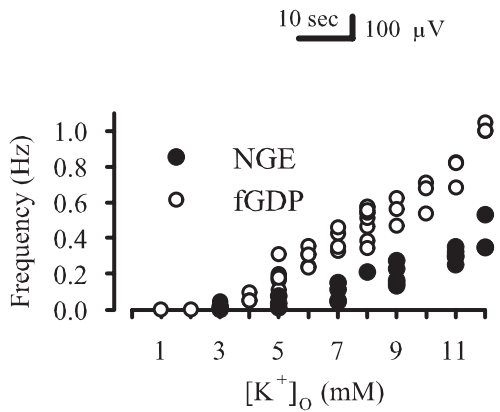

$\mathbf{B}_{1}$
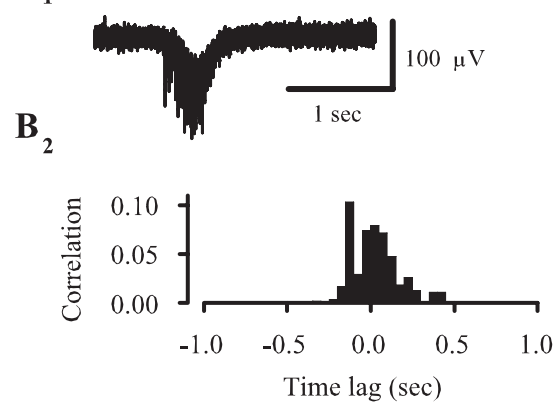

D

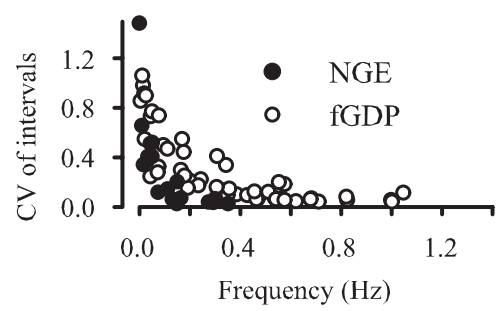

Figure 7. Endogenous GABA facilitates network activity. $A$, fp recording showing a blockade of fGDPs by $10 \mu \mathrm{m}$ bicuculline (bic). A subsequent elevation of $\left[\mathrm{K}^{+}\right]_{0}$ induces a recovery of synchronous population activity in the complete absence of $\mathrm{GABA}_{A}$ transmission (NGEs; bandpass, $0.2-15 \mathrm{~Hz}$; see Results). $\boldsymbol{B}_{1}$, fp recording showing a single NGE ([K $\left.{ }^{+}\right]_{0}=7 \mathrm{~mm}$ ). $\boldsymbol{B}_{2}$, Crosscorrelation histogram of spikes versus slow, negative $\mathrm{fp}$ shifts obtained from four recordings. $C$, Scatter plot showing mean NGE frequency versus $\left[\mathrm{K}^{+}\right]_{0}(\mathbf{O})$ from eight experiments with 22 recordings at different $\left[\mathrm{K}^{+}\right]_{0}$. To facilitate comparison, data from the corresponding plot related to fGDPs from Figure $3 \mathrm{C}$ is also shown $\left(\bigcirc\right.$; from 15 experiments with 56 recordings at different $\left.\left[\mathrm{K}^{+}\right]_{0}\right)$. $D$, Scatter plot of the $C V$ of NGE intervals versus mean frequency $(-)$ from the same eight experiments as in $C$. Corresponding data from Figure $3 D$ related to $\mathrm{fGDPs}$ is also shown $(\bigcirc)$.

A

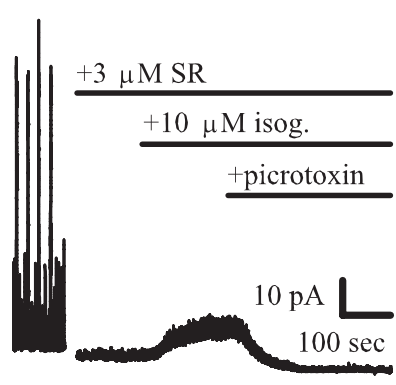

B
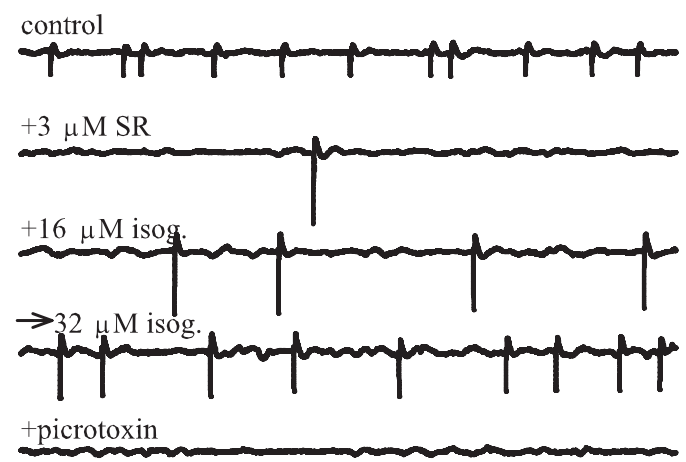

$10 \mathrm{sec} 100 \mu \mathrm{V}$

Figure 8. Tonic GABA action in the absence of interneuronal input enhances $\mathrm{fGDPs}$. $A$, Voltage-clamp recording $(0 \mathrm{mV}$; lowchloride filling solution) under control conditions, with the addition of $3 \mu \mathrm{M}$ SR 95531, with a subsequent addition of isoguvacine $(10 \mu \mathrm{M}$ ), and finally with the addition of picrotoxin. $\boldsymbol{B}$, Traces of an fp recording under similar conditions as in $\boldsymbol{A}$ (bandpass, 0.2-15 Hz). SR, SR 95531; isog., isoguvacine.

presence of both glutamatergic and GABAergic ionotropic antagonists. Moreover, bursting at a frequency of $\sim 0.3 \mathrm{~Hz}$ also takes place in the absence of drugs, indicating that the underlying intrinsic properties essentially govern the firing patterns of the CA3 pyramids during ongoing synaptic activity.

The idea that intrinsic bursting of CA3 pyramids drives and shapes fGDPs in the immature hippocampus is in full agreement with the fact that ionotropic glutamatergic transmission is obligatory for the generation of the network activity underlying fGDPs but not for unit bursting. In particular, the preferred frequency of unit activity seen within inter-fGDP intervals (asynchronous bursts) and in the presence of glutamate blockers is similar to the preferred frequency of fGDPs. In contrast, blocking $\mathrm{GABA}_{\mathrm{A}}$-mediated transmission blocks spontaneous unit firing by membrane hyperpolarization, whereas a subsequent depolarization caused by increasing $\left[\mathrm{K}^{+}\right]_{\mathrm{o}}$ induces a recovery of unit activity. This is, of course, to be expected from the voltage-dependent bursting property of the CA3 pyramids and the presence of a tonic $\mathrm{GABA}_{\mathrm{A}}$ mediated conductance. In accordance with the behavior of individual neurons, hyperpolarization produced by decreasing $\left[\mathrm{K}^{+}\right]_{\mathrm{o}}$ or blocking $\mathrm{GABA}_{\mathrm{A}}$ receptors had an inhibitory action on fGDPs. Depolarization via increasing $\left[\mathrm{K}^{+}\right]_{\mathrm{o}}$ or exogenous $\mathrm{GABA}_{\mathrm{A}}$ activation not only produced an increase in mean fGDP frequency but also an enhancement of their temporal stability at more than $\sim 0.2-0.3 \mathrm{~Hz}$, which is the frequency of rhythmic intrinsic bursting of the immature CA3 pyramids.

The present data indicate that the interneuronal network is not endowed with intrinsic properties that are critical for the $\sim 0.3 \mathrm{~Hz}$ rhythmicity. Indeed, the conspicuous rhythmic sGABA-PSC activity that was seen at the preferred fGDP frequency was abolished by glutamate receptor antagonists (Fig. 4). Hence, the interneurons appear to be entrained to their $\sim 0.3 \mathrm{~Hz}$ population activity during fGDPs by the rhythmic input from pyramidal neurons. In the presence of kynurenic acid (a competitive glutamate blocker), metabotropic glutamate receptor agonists, focal electric stimulation, or application of GABA or AMPA have been shown to induce intracellularly recorded bicuculline-sensitive bursts (Strata et al., 1995; Bolea et al., 1999). This might be taken as evidence for an interneuronal pacemaker of fGDPs. However, the experiments mentioned above were performed using intracellular recordings that cannot unambiguously distinguish cellular-level bursts from network events (see Materials and Methods). Notably, GYKI 53655 (a noncompetetive glutamate antagonist) completely blocked these intracellularly recorded bursts (Bolea et al., 1999). Thus, all of the available data indicate that ionotropic glutamate receptor-mediated transmission is required for fGDP generation.

In addition to the results discussed above, the lack of a requirement for a temporally patterned $\mathrm{GABA}_{\mathrm{A}}$ action in promoting fGDPs was also clearly evident in experiments in which the effects of isoguvacine and elevated $\left[\mathrm{K}^{+}\right]_{\mathrm{o}}$ were compared in the presence of $\mathrm{GABA}_{\mathrm{A}}$ antagonists. In a complete block of $\mathrm{GABA}_{\mathrm{A}^{-}}$ mediated transmission by bicuculline, elevation of $\left[\mathrm{K}^{+}\right]_{\mathrm{o}}$ invariably restored population activity with temporal properties simi- 
lar to those of fGDPs. The competitive $\mathrm{GABA}_{\mathrm{A}}$ antagonist SR 95531 also enabled us to make experiments in which an increase in tonic $\mathrm{GABA}_{\mathrm{A}}$ action was imposed in the complete absence of phasic and a partial block of tonic $\mathrm{GABA}_{\mathrm{A}}$-mediated transmission (Stell and Mody, 2002) (Fig. 8A,B). Initially, SR 95531 inhibited fGDPs, but rhythmic network events were strongly activated by a following application of isoguvacine. All of the observations discussed above are to be expected on the basis of the simple assumption that the voltage-dependent intrinsic bursting of CA3 pyramids is the proximal site of action of any depolarizing or hyperpolarizing influence in the chain of events that leads to changes in fGDP frequency and temporal stability.

It is also worth noting that because $\mathrm{GABA}_{\mathrm{A}}$ antagonists had an inhibitory action also at the level of unit bursting, the view that desynchronization would account for their inhibitory action on fGDPs is not supported. A decrease in the general level of excitation (i.e., of nonpatterned, facilitatory GABAergic action) can fully account for the observed effect. This is also supported by the finding that a subsequent elevation of $\left[\mathrm{K}^{+}\right]_{\mathrm{o}}$ invariably induced population bursts. In contrast, ionotropic glutamate antagonists had qualitatively a very different effect because they lead to desynchronization (Ben Ari et al., 1989; Hollrigel et al., 1998; Bolea et al., 1999; Lamsa et al., 2000; Khazipov et al., 2001) of pyramidal cells and interneurons also in elevated $\left[\mathrm{K}^{+}\right]_{\mathrm{o}}$ but did not block spontaneous activity of these cells.

An interesting novel finding in the present work was that in the immature CA3 pyramidal neurons, endogenous GABA activates a large tonic (extrasynaptic) conductance (Fig. 5) (Brickley et al., 1996; Farrant and Nusser, 2005). Application of bicuculline increased the steady-state input resistance, and during inter-GDP intervals, the tonic component was $\sim 87 \%$ from the total $\mathrm{GABA}_{\mathrm{A}^{-}}$ mediated charge transfer. The substantial tonic GABA conductance in the immature CA3 pyramids under control conditions reflects the presence of nondesensitizing high-affinity receptors (Stell and Mody, 2002) and is in excellent agreement with the potent, dose-dependent, long-term actions of 4-32 $\mu \mathrm{M}$ isoguvacine (Figs. $3 A, 8 A, B$ ) and other $\mathrm{GABA}_{\mathrm{A}}$ agonists (Khalilov et al., 1999; Lamsa et al., 2000). Interestingly, previous results (Valeyev et al., 1993; Demarque et al., 2002; Owens and Kriegstein, 2002) on immature neurons have indicated that tonic GABA actions develop before phasic synaptic GABAergic transmission. The former is thought to have a trophic action that depends on depolarization and on consequent downstream signal transduction (Owens and Kriegstein, 2002).

According to the present data, fGDP generation is initiated by any depolarization sufficient to activate voltage-dependent intrinsic bursts in a subpopulation containing perhaps just a few pyramidal cells (Traub and Wong, 1982; cf. Miles and Wong, 1983). This will then lead to (1) recurrent pyramidal excitation (Miles and Wong, 1983; Bolea et al., 1999) and (2) excitation of interneurons (Khazipov et al., 1997), which are likely to impose an additional, recurrent GABAergic feedback drive on the immature pyramidal neurons (Fig. 4B) (Ben Ari et al., 1989; Khalilov et al., 1999; Menendez de la Prida and Sanchez-Andres, 1999, 2000). Thus, a rapid buildup of excitation and synchronization among the population of pyramidal neurons and interneurons produces an fGDP [see Traub and Wong (1982) for data on the disinhibited mature hippocampus]. If a tonic depolarization is imposed on the pyramids, the fGDPs interval is determined by the intrinsic-burst interval of the pyramidal cells as indicated by the present data (Figs. 2-4).

Under control (physiological) conditions, the tonic action of GABA plays a major role in the depolarization of the CA3 pyra- mids. Obviously, our data do not exclude the possibility that phasic GABAergic input can initiate intrinsic pyramidal bursts (Ben Ari et al., 1989; Khazipov et al., 1997; cf. Menendez de la Prida and Sanchez-Andres, 1999, 2000; Ben Ari, 2001). Notably, however, we show that the interneuronal network does not generate a temporally patterned input on the pyramidal neurons to pace fGDP activity. An important novel finding in the present study is that a nonpatterned depolarizing GABAergic drive on the pyramidal network can fully account for the well known excitatory role of GABAergic transmission in fGDP generation. Our present data also suggest that the mechanisms generating fGDPs have striking similarities with those underlying interictal-like activity driven by CA3 pyramidal neurons in the mature hippocampus under conditions in which $\mathrm{GABA}_{\mathrm{A}}$ receptors are blocked, or in the presence of high $\left[\mathrm{K}^{+}\right]_{\mathrm{o}}$ (Traub and Wong, 1982; Aradi and Maccaferri, 2004). Furthermore, excitatory (depolarizing) GABAergic actions in pyramidal pacemakers of the subiculum generate interictal activity in human mesial temporal lobe epilepsy (Cohen et al., 2002, 2003). The above observations lead to an intriguing vision, in which functionally excitatory GABAergic transmission acting on pyramidal pacemakers is a common denominator of two kinds of extensively studied spontaneous network events: (1) the fGDPs generated by the immature hippocampus and (2) the interictal activity in the mature epileptic hippocampus, where GABAergic transmission has reacquired neonatal features in response to neuronal damage (Rivera et al., 2002, 2004; Cohen et al., 2003; Payne et al., 2003).

\section{References}

Aradi I, Maccaferri G (2004) Cell type-specific synaptic dynamics of synchronized bursting in the juvenile CA3 rat hippocampus. J Neurosci 24:9681-9692.

Bai D, Zhu G, Pennefather P, Jackson MF, MacDonald JF, Orser BA (2001) Distinct functional and pharmacological properties of tonic and quantal inhibitory postsynaptic currents mediated by gamma-aminobutyric acid(A) receptors in hippocampal neurons. Mol Pharmacol 59:814-824.

Barry PH (1994) JPCalc, a software package for calculating liquid junction potential corrections in patch-clamp, intracellular, epithelial and bilayer measurements and for correcting junction potential measurements. J Neurosci Methods 51:107-116.

Ben Ari Y (2001) Developing networks play a similar melody. Trends Neurosci 24:353-360.

Ben Ari Y, Cherubini E, Corradetti R, Gaiarsa JL (1989) Giant synaptic potentials in immature rat CA3 hippocampal neurones. J Physiol (Lond) 416:303-325.

Bolea S, Avignone E, Berretta N, Sanchez-Andres JV, Cherubini E (1999) Glutamate controls the induction of GABA-mediated giant depolarizing potentials through AMPA receptors in neonatal rat hippocampal slices. J Neurophysiol 81:2095-2102.

Brickley SG, Cull-Candy SG, Farrant M (1996) Development of a tonic form of synaptic inhibition in rat cerebellar granule cells resulting from

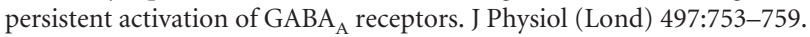

Cohen I, Navarro V, Clemenceau S, Baulac M, Miles R (2002) On the origin of interictal activity in human temporal lobe epilepsy in vitro. Science 298:1418-1421.

Cohen I, Navarro V, Le Duigou C, Miles R (2003) Mesial temporal lobe epilepsy: a pathological replay of developmental mechanisms? Biol Cell 95:329-333.

Demarque M, Represa A, Becq H, Khalilov I, Ben Ari Y, Aniksztejn L (2002) Paracrine intercellular communication by a $\mathrm{Ca}^{2+}$ and SNAREindependent release of GABA and glutamate prior to synapse formation. Neuron 36:1051-1061.

Draguhn A, Traub RD, Schmitz D, Jefferys JG (1998) Electrical coupling underlies high-frequency oscillations in the hippocampus in vitro [see comments]. Nature 394:189-192.

Dzhala VI, Staley KJ (2003) Excitatory actions of endogenously released GABA contribute to initiation of ictal epileptiform activity in the developing hippocampus. J Neurosci 23:1840-1846. 
Farrant M, Nusser Z (2005) Variations on an inhibitory theme: phasic and tonic activation of $\mathrm{GABA}_{\mathrm{A}}$ receptors. Nat Rev Neurosci 6:215-229.

Feller MB (1999) Spontaneous correlated activity in developing neural circuits. Neuron 22:653-656.

Garaschuk O, Hanse E, Konnerth A (1998) Developmental profile and synaptic origin of early network oscillations in the CA1 region of rat neonatal hippocampus. J Physiol (Lond) 507:219-236.

Garaschuk O, Linn J, Eilers J, Konnerth A (2000) Large-scale oscillatory calcium waves in the immature cortex. Nat Neurosci 3:452-459.

Hollrigel GS, Ross ST, Soltesz I (1998) Temporal patterns and depolarizing actions of spontaneous $\mathrm{GABA}_{\mathrm{A}}$ receptor activation in granule cells of the early postnatal dentate gyrus. J Neurophysiol 80:2340-2351.

Hutcheon B, Yarom Y (2000) Resonance, oscillation and the intrinsic frequency preferences of neurons. Trends Neurosci 23:216-222.

Kandler K (2004) Activity-dependent organization of inhibitory circuits: lessons from the auditory system. Curr Opin Neurobiol 14:96-104.

Kasyanov AM, Safiulina VF, Voronin LL, Cherubini E (2004) GABAmediated giant depolarizing potentials as coincidence detectors for enhancing synaptic efficacy in the developing hippocampus. Proc Natl Acad Sci USA 101:3967-3972.

Katz LC, Crowley JC (2002) Development of cortical circuits: lessons from ocular dominance columns. Nat Rev Neurosci 3:34-42.

Khalilov I, Dzhala V, Ben Ari Y, Khazipov R (1999) Dual role of GABA in the neonatal rat hippocampus. Dev Neurosci 21:310-319.

Khazipov R, Leinekugel X, Khalilov I, Gaiarsa JL, Ben Ari Y (1997) Synchronization of GABAergic interneuronal network in CA3 subfield of neonatal rat hippocampal slices. J Physiol (Lond) 498:763-772.

Khazipov R, Esclapez M, Caillard O, Bernard C, Khalilov I, Tyzio R, Hirsch J, Dzhala V, Berger B, Ben Ari Y (2001) Early development of neuronal activity in the primate hippocampus in utero. J Neurosci 21:9770-9781.

Khazipov R, Khalilov I, Tyzio R, Morozova E, Ben Ari Y, Holmes GL (2004) Developmental changes in GABAergic actions and seizure susceptibility in the rat hippocampus. Eur J Neurosci 19:590-600.

Khirug S, Huttu K, Ludwig A, Smirnov S, Voipio J, Rivera C, Kaila K, Khiroug L (2005) Distinct properties of functional KCC2 expression in immature mouse hippocampal neurons in culture and in acute slices. Eur J Neurosci 21:899-904.

Kyrozis A, Reichling DB (1995) Perforated-patch recording with gramicidin avoids artifactual changes in intracellular chloride concentration. J Neurosci Methods 57:27-35.

Lamsa K, Palva JM, Ruusuvuori E, Kaila K, Taira T (2000) Synaptic GABA A activation inhibits AMPA-kainate receptor-mediated bursting in the newborn (P0-P2) rat hippocampus. J Neurophysiol 83:359-366.

Leinekugel X, Khazipov R, Cannon R, Hirase H, Ben Ari Y, Buzsaki G (2002) Correlated bursts of activity in the neonatal hippocampus in vivo. Science 296:2049-2052.

Llinas RR (1988) The intrinsic electrophysiological properties of mammalian neurons: insights into central nervous system function. Science 242:1654-1664.

Marder E, Bucher D (2001) Central pattern generators and the control of rhythmic movements. Curr Biol 11:R986-R996.

Menendez de la Prida L, Sanchez-Andres JV (1999) Nonlinear frequencydependent synchronization in the developing hippocampus. J Neurophysiol 82:202-208.

Menendez de la Prida L, Sanchez-Andres JV (2000) Heterogeneous populations of cells mediate spontaneous synchronous bursting in the developing hippocampus through a frequency-dependent mechanism. Neuroscience 97:227-241.

Menendez de la Prida L, Bolea S, Sanchez-Andres JV (1998) Origin of the synchronized network activity in the rabbit developing hippocampus. Eur J Neurosci 10:899-906.
Miles R, Wong RK (1983) Single neurones can initiate synchronized population discharge in the hippocampus. Nature 306:371-373.

O'Donovan MJ (1999) The origin of spontaneous activity in developing networks of the vertebrate nervous system. Curr Opin Neurobiol 9:94-104

Owens DF, Kriegstein AR (2002) Is there more to GABA than synaptic inhibition? Nat Rev Neurosci 3:715-727.

Payne JA, Rivera C, Voipio J, Kaila K (2003) Cation-chloride cotransporters in neuronal communication, development and trauma. Trends Neurosci 26:199-206.

Penn AA, Shatz CJ (1999) Brain waves and brain wiring: the role of endogenous and sensory-driven neural activity in development. Pediatr Res 45:447-458.

Rivera C, Voipio J, Payne JA, Ruusuvuori E, Lahtinen H, Lamsa K, Pirvola U, Saarma M, Kaila K (1999) The $\mathrm{K}^{+} / \mathrm{Cl}^{-}$co-transporter KCC2 renders GABA hyperpolarizing during neuronal maturation [see comments]. Nature 397:251-255.

Rivera C, Li H, Thomas-Crusells J, Lahtinen H, Viitanen T, Nanobashvili A, Kokaia Z, Airaksinen MS, Voipio J, Kaila K, Saarma M (2002) BDNFinduced $\operatorname{TrkB}$ activation down-regulates the $\mathrm{K}^{+}-\mathrm{Cl}^{-}$cotransporter KCC2 and impairs neuronal $\mathrm{Cl}^{-}$extrusion. J Cell Biol 159:747-752.

Rivera C, Voipio J, Thomas-Crusells J, Li H, Emri Z, Sipila S, Payne JA, Minichiello L, Saarma M, Kaila K (2004) Mechanism of activitydependent downregulation of the neuron-specific $\mathrm{K}-\mathrm{Cl}$ cotransporter KCC2. J Neurosci 24:4683-4691.

Semyanov A, Walker MC, Kullmann DM (2003) GABA uptake regulates cortical excitability via cell type-specific tonic inhibition. Nat Neurosci 6:484-490.

Smith JC, Ellenberger HH, Ballanyi K, Richter DW, Feldman JL (1991) PreBotzinger complex: a brainstem region that may generate respiratory rhythm in mammals. Science 254:726-729.

Spitzer NC, Root CM, Borodinsky LN (2004) Orchestrating neuronal differentiation: patterns of $\mathrm{Ca}^{2+}$ spikes specify transmitter choice. Trends Neurosci 27:415-421.

Stell BM, Mody I (2002) Receptors with different affinities mediate phasic and tonic $\mathrm{GABA}_{\mathrm{A}}$ conductances in hippocampal neurons. J Neurosci 22:223RC(1-5).

Steriade M, McCormick DA, Sejnowski TJ (1993) Thalamocortical oscillations in the sleeping and aroused brain. Science 262:679-685.

Strata F, Sciancalepore M, Cherubini E (1995) Cyclic AMP-dependent modulation of giant depolarizing potentials by metabotropic glutamate receptors in the rat hippocampus. J Physiol (Lond) 489:115-125.

Stuart GJ, Dodt HU, Sakmann B (1993) Patch-clamp recordings from the soma and dendrites of neurons in brain slices using infrared video microscopy. Pflügers Arch 423:511-518.

Traub RD, Wong RK (1982) Cellular mechanism of neuronal synchronization in epilepsy. Science 216:745-747.

Tyzio R, Represa A, Jorquera I, Ben Ari Y, Gozlan H, Aniksztejn L (1999) The establishment of GABAergic and glutamatergic synapses on CA1 pyramidal neurons is sequential and correlates with the development of the apical dendrite. J Neurosci 19:10372-10382.

Tyzio R, Ivanov A, Bernard C, Holmes GL, Ben Ari Y, Khazipov R (2003) Membrane potential of CA3 hippocampal pyramidal cells during postnatal development. J Neurophysiol 90:2964-2972.

Valeyev AY, Cruciani RA, Lange GD, Smallwood VS, Barker JL (1993) Clchannels are randomly activated by continuous GABA secretion in cultured embryonic rat hippocampal neurons. Neurosci Lett 155:199-203.

Yamada J, Okabe A, Toyoda H, Kilb W, Luhmann HJ, Fukuda A (2004) Cluptake promoting depolarizing GABA actions in immature rat neocortical neurones is mediated by NKCC1. J Physiol (Lond) 557:829-841. 